\title{
Multiletramentos em contextos multisseriais: uma abordagem sobre Educação do Campo no semiárido baiano
}

\author{
Multiletramentsin multiserial contexts: an approach on field education in the
} bahia's semiarid

\begin{abstract}
Resumo: O presente artigo apresenta os multiletramentos como mecanismos de exercício social da leitura e escrita, e sua viabilidade no contexto das escolas multisseriadas do campo. Entendemos que a heterogeneidade do funcionamento das classes multisseriadas favorece a interação entre os educandos e as ferramentas tecnológicas como aliadas para a concretização de uma educação enraizada - e por isso, contextualizada - nesses espaços. A aquisição da leitura, pensada como letramento e multiletramento excede a ideia tradicionalmente aceita de que nas comunidades rurais as pessoas apenas precisam "saber ler". As interações sociais através da linguagem, no âmbito das comunicações virtuais situam-se como ferramenta de emancipação e autonomia, portanto devem ser acessíveis a todos os educandos. Nesse sentido, o artigo tem como objetivo: refletir a importância de uso dos multiletramentos, na formação de sujeitos leitores/produtores de textos críticos, em turmas multisseriadas, a partir das vivências dos educados com as ferramentas tecnológicas. A pesquisa é bibliográfica, apresentando ainda elementos da observação participante, realizada em uma turma multisseriada do campo, na escola Nossa Senhora Rainha dos Anjos - Juazeiro - BA. O percurso metodológico ocorreu por meio da revisão de literatura e análises de conversas dos alunos registradas no Diário de Campo durante a observação participante. Para nos ajudar a pensar sobre a temática contamos com as contribuições de: Rojo (2012), Soares (2020), D' Agostini (2015), Hage (2014), Reis (2011), Freire (1989), dentre outros autores.
\end{abstract}

Palavras-chave: Interações sociais. Linguagem. Contextualização. Multiletramentos. Educação do Campo.

\begin{abstract}
This article presents the multi-tools as mechanisms for the social exercise of reading and writing, and their viability in the context of multi-grade schools in the countryside. We understand that the heterogeneity in the functioning of the multi-grade classes favors the interaction between students and technological tools as allies for the realization of an education rooted - and therefore, contextualized - in these spaces. The acquisition of reading, thought of as literacy and multiliteracy, goes beyond the traditionally accepted idea that in rural communities people just need to "know how to read". Social interactions through language, within the scope of virtual communications are situated as a tool of emancipation and autonomy, therefore they must be accessible to all students. In this sense, the article aims to: reflect the importance of using multicourses, in the formation of readers / producers of critical texts, in multi-grade classes, from the experiences of the educated with the technological tools. The research is bibliographic, also presenting elements of participant observation, carried out in a multiserial class from the field, at the Nossa Senhora Rainha dos Anjos school - Juazeiro - BA. The methodological path occurred through literature review and analysis of students' conversations recorded in the Diário de Campo during participant observation. To help us think about the theme we have the contributions of: Rojo (2012), Soares (2020), D’Agostini (2015), Hage (2014), Reis (2011), Freire (1989), among other authors.
\end{abstract}


Keywords: Social interactions. Language. Contextualization. Multi-tools. Rural Education.

\section{Introdução}

Neste artigo, apresentamos uma discussão acerca dos processos de letramento que ocorrem nas escolas multisseriadas, localizadas no campo. 0 estudo teve origem a partir de releituras nas anotações registradas no Diário de Campo durante a observação participante, 02 (dois) anos após a apresentação da pesquisa de mestrado: O diálogo entre a educação contextualizada e a aprendizagem nas práticas pedagógicas desenvolvidas em classes multisseriadas.

Nos registros escritos detectou-se que o aluno $X$ trouxe em um Pendrive, um evento de letramento, (o batizado do irmãozinho). O mesmo solicitou ao professor permissão para utilizar um dos computadores da escola, que não tem internet e, mostrar aos colegas o acontecimento. O docente por sua vez disse que aguardasse o intervalo que a sala dos computadores seria aberta. Perguntei ao menino se ele permitia que a professora, no caso a pesquisadora, também pudesse assistir o que ele queria mostrar aos colegas de sala. O mesmo disse: "venha professora conhecer meu irmão". Antes de ligar o computador o garoto não parava de falar sobre o fato, demonstrando a sua felicidade ao ter consigo o registro do evento e ainda compartilhar aquele momento. Assim que as imagens começaram a aparecer na tela do computador ele ia narrando o que aconteceu: o padre reclamando das crianças correndo na igreja, o nome das pessoas presentes, o local onde aconteceu o evento (Igreja de Juazeiro - BA.) os nomes dos padrinhos, a roupa do irmãozinho (uma camisa de manga comprida) e etc. Quando passa uma imagem da criança sendo batizada, ele se emociona e exclama: tadinho!!! Essa careta é por causa do sal! Terminada a sessão fotografia ele diz: "o batismo foi em Juazeiro, mas a festa, a comida foi lá em casa com muito churrasco, só que não tá aqui, apontando para o pendrive". (DIÁRIO DE CAMPO - ABRIL/2017).

Outros eventos de letramento social, vivenciados por 02 (duas) das 17 (dezessete) crianças matriculadas, que tinham aparelho celular e com registros no Diário de Campo foram: o uso do aplicativo Whatsapp via celular, o uso de 
jogos diversos como os da Barbie e Bem 10, além da conversa via celular com parentes e amigos das comunidades distantes. O uso do Whatsapp, segundo as crianças, só era possível quando iam para a sede de Juazeiro. Já o celular para as conversações, as mesmas nos informaram que, na comunidade de Maniçoba, onde esta localizada a escola investigada, o sinal do aparelho é muito ruim e as pessoas só conseguem falar quando sobem em algum lugar alto, porque assim dá pra ouvir melhor as pessoas. E ainda afirmaram sorrindo: "todo mundo aqui, sobe nas árvores, na casa, em serra só pra conversar". (DIÁRIO DE CAMPOAGOSTO/2017).

Portanto, em face dos eventos apontados, se fez necessária a discussão sobre "multiletramentos" com base na realidade dos educandos, uma vez que as práticas sociais de leitura e escrita vêm modificando e agregando novas ferramentas, em vista da informatização dos processos de comunicação, dentro da escola, em suas variadas formas. Esses mecanismos podem ser aliados nas aprendizagens em sala de aula, independente dos níveis de escolarização.

Trazemos, o conceito de "multiletramento" como forma de evidenciar a prática de leitura e escrita no ambiente das multisséries presentes nas comunidades do campo, que ocorrem de diversas formas, contemplando não apenas as aulas de linguagem (Língua Portuguesa), porém, todas as áreas do conhecimento se integram e interagem no cotidiano dos estudantes e professores no cotidiano escolar.

O cenário da discussão ora apresentada é o campo, uma vez que conforme dados de pesquisadores (D'AGOSTINI, 2015), constatam a existência da maioria dessa modalidade de ensino. Verificamos também a mesma situação no município de Juazeiro-BA, em relação às multisséries. A pesquisa ${ }^{1}$ de que trata este trabalho retrata uma realidade observada no Distrito de Maniçoba, no referido município, localizado no Território Semiárido Baiano. A metodologia utilizada na referida pesquisa, teve como um dos eixos a observação participante, cujo objetivo foi identificar práticas pedagógicas contextualizadas

1 A pesquisa de campo na Escola Municipal Nossa Senhora Rainha dos Anjos, foi desenvolvida durante o ano letivo de 2017, sendo parte do estudo desta autora desenvolvido no curso de Mestrado em Educação, Cultura e Territórios Semiáridos no Campus III da Universidade do Estado da Bahia (UNEB). 
na escola escolhida. Acerca do lócus do qual se fala, Carvalho (2012, p. 117) expõe:

\begin{abstract}
O Semiárido Brasileiro do século XXI ainda é demarcado pela forte exclusão social, mas por outro lado, um crescente posicionamento crítico e propositivo da sociedade civil. As lutas contra a pobreza, as injustiças sociais e as formas de ação e intervenção descontextualizadas por parte do Estado, moldaram um papel proativo desse segmento social, que além de pressionar a democratização dos programas de desenvolvimento, passa a agir pela abertura de sua participação e gestão nos processos de elaboração e implementação de programas para o território.
\end{abstract}

Trazemos, neste trabalho, a necessidade da "contextualização" das práticas pedagógicas, ou "contextualização dos saberes". Esse é um conceito que implica na aproximação entre os conteúdos de ensino e a realidade objetiva dos estudantes, proporcionando a apropriação de conhecimentos relacionados à sua vida cotidiana, ancorados em saberes universal. Para tanto, o saber ler e escrever de forma abrangente, ancorados nos diversos suportes tecnológicos, é condição básica para que os aprendizes possam expandir sua atuação social.

Vale ressaltar que, a educação contextualizada tem sido apontada como projeto eficaz, principalmente no campo, abrindo discussões importantes, inclusive em Universidades públicas, a exemplo da UNEB, Campus III, onde um curso de Mestrado a elegeu como objeto de estudo. Por sua vez, o Departamento de Ciências Humanas da UNEB de Juazeiro-BA, desde a criação da Rede de Educação do Semiárido (RESAB), discute e fundamenta no âmbito das reflexões e práticas junto os diversos atores sociais que a compõe, os princípios norteadores da Educação Contextualizada para Conivência com 0 Semiárido Brasileiro (SAB

Vale ressaltar que, em grande parte das áreas rurais, as comunicações virtuais já se tornaram comuns, estas podem ser também aliadas na construção de processos de multiletramentos, não somente incluindo ferramentas digitais como aplicativos de celular, mas possibilitando interação com novos e múltiplos suportes de leitura como jornais, revistas, blogs, além de gêneros como o e-mail, vídeos, documentários, e-books, jogos lúdicos e outros disponibilizados online. 
Abordamos o multiletramento como prática possível e favorável na multissérie, uma vez que a presença de estudantes com variados níveis de conhecimento e uma considerável interação entre si, facilita a diversidade de ferramentas, suportes e gêneros, criando, portanto, oportunidades de leituras.

A sala multisseriada, antes mesmo da chegada dos meios tecnológicos e midiáticos, hoje popularizados, já tem sido lugar de interações e múltiplas formas de letramentos, a partir das experiências compartilhadas em seus contextos de atuação, conforme será descrito adiante. Neste artigo, de tal maneira, discutimos a relação entre o multiletramento e a multissérie como efetivação de um projeto de educação contextualizada em que a leitura contemple as necessidades de interações sociais dos educandos.

\section{Letramento, multiletramento e significados}

Cada processo de letramento é único, individual. As crianças aprendem a se relacionar com o texto escrito a partir de suas experiências, do contato com materiais e objetos de leitura (tais como vivências culturais de leitura, vídeo, teatro, aparelho celular e demais ferramentas culturais). Grupos sociais diferentes escrevem e lêem de forma diferente seus textos, assim como em diferentes contextos, grupos sociais se envolvem de maneiras variadas com eventos de leitura. A atribuição de sentido à escrita, e, de igual maneira, a produção textual de qualquer gênero, não ocorre de forma homogênea para indivíduos e grupos sociais dentro dos seus contextos. Essa afirmação encontrase principalmente em Street (2014), que trabalha com o conceito de "letramento social".

Há algum tempo, nos meios acadêmicos estabeleceu-se uma discussão acerca das diferenças entre os conceitos de alfabetização e letramento. Ser alfabetizado pode ser considerado tão somente ler e escrever. Ou seja, decodificar letras/palavras na língua materna e escrever o básico. Porém, ser letrado requer a utilização da língua escrita enquanto meio efetivo de exercer interações sociocomunicativas.

Soares (2004) defende que letramento é o resultado da ação de "letrarse", se dermos ao verbo "letrar-se" o sentido "de torna-se letrado". Compreende- 
se, portanto, que, o ato de "letrar-se" é de extrema importância para toda criança em fase de escolarização, assim como para qualquer pessoa nas distintas fases da vida. Adentrando ao universo da leitura-escrita, o indivíduo passa a sentir-se parte do mundo, ampliando o seu conhecimento, podendo ser um agente de transformação a partir do seu próprio contexto.

De tal maneira, o letramento ocorre dentro de variadas possibilidades, tendo como base o que o estudante já trouxe do seu cotidiano para a escola. Esta, por sua vez, tem a função de desenvolver as diferentes práticas de linguagem, contribuindo para que os estudantes se apropriem do conhecimento linguístico em vista da formação do sujeito-leitor que se tornará apto praticar a leitura, assim como a escrita, com propriedade, nos diversos contextos possíveis.

Os meios utilizados para o letramento escolar têm se diversificado ao longo do tempo. Com o aumento da informatização, as escolas, de forma mais abrangente na cidade - porém, mas também, muito lentamente no campo - têm adotado tecnologias da informação como acesso aos vários letramentos. É evidente que isso não se faz tão equilibradamente na distribuição, pois muitas vezes, os equipamentos chegam (como é o caso da escola pesquisada), mas não há uma rede de acesso, que permita a navegação na web, como deveria acontecer. Assim, desde que chegando com a devida qualidade, o uso da internet pode representar um salto, ou seja, uma potencialização a mais no aproveitamento dos conteúdos trabalhados pela escola mediante uma aprendizagem que faça sentido e que produza significado para os estudantes.

Há várias iniciativas que podem ser desenvolvidas com uso da mediação tecnológica, na potencialização das aprendizagens nas escolas e práticas pedagógicas do campo, e isso pode ser exemplificado com a utilização de hipertextos, vídeos, pesquisas, e atualmente as lives, muito utilizadas ultimamente, devido ao cenário da Pandemia da COVID-19 no contexto educacional e artístico e, ainda aplicativos diversos, com uma grande variedade de funções como edição textual. A produção de textos coletivamente também é uma ação possível, mediante o uso de ferramentas apropriadas de atividades em grupos de estudantes. Esse é apenas um exemplo de novas práticas de 
lecto-escrita em uso na sociedade atualmente e que podem constituir-se no diferencial em sala de aula, em diferentes contextos, com momentos presenciais entre o professor e os alunos.

Para Rojo (2012), o conceito de multiletramento relaciona-se com a multiplicidade das populações e a multiplicidade semiótica de constituições textuais presente na sociedade. De tal modo, essas características fazem com que o processo de produção não seja mais exclusivamente linguístico, pois, integram movimento, imagem e som, podendo ser, inclusive, colaborativa, feita a várias mãos.

Tratando-se da presença de mecanismos de multiletramento, é importante registrar que o ciberespaço, pela sua condição de "multimodalidade" de gêneros, possibilita a ampliação do olhar do estudante e da própria atuação deste no que diz respeito à sua formação como sujeito leitor, em vista do grande leque de experiências que proporciona.

Entretanto, o que consideramos como multiletramento ainda não chegou a ser um tema amplamente discutido e compreendido no ambiente acadêmico, menos ainda nos espaços escolares da educação básica. Dessa forma, salientamos ainda que à escola compete favorecer que os educandos tenham acesso a diferentes práticas sociais de linguagem, contemplando a leitura (assim como a escrita) em diversos contextos.

Garcia; Silva; Felício; (2012), descrevem que os estudos sobre multiletramento só vieram a ganhar força no Brasil após a chegada do século $\mathrm{XXI}$, quando se passa a avançar da perspectiva cognitiva para a perspectiva discursiva. O próprio letramento também tem uma história recente dentre os estudos brasileiros, vindo a ser mais conhecido através dos estudos de Brian Street, que aborda "os letramentos" no plural, indicando que estes são múltiplos e variam no tempo, no espaço, e nas diversas situações de interação linguística.

Dessa forma, houve avanço na compreensão do alfabetismo para situar as práticas sociais de leitura como eventos de letramento. Foi o grupo de Nova Londres - fundado em 1996 nos Estados Unidos - que desenvolveu as abordagens dos "multiletramentos". Na compreensão de Lima e Lima (2016, p. 91), "Os multiletramentos consideram que, de acordo com as condições 
socioculturais, são necessárias mais que habilidades para resolver alguns dos problemas que os estudantes enfrentam nas atividades de ensinoaprendizagem".

Tradicionalmente, tem sido a escola a porta para o letramento; entretanto, vale registrar outros possíveis espaços para os indivíduos acessar diferentes práticas de leitura, inclusive através de meios digitais. É o caso, por exemplo, das lan houses, e mais recentemente, das redes sociais disponíveis por aplicativos de celular. Para Garcia; Silva; Felício; (2012), saindo-se do conceito de letramento com uma conotação exclusivamente grafocêntrica, a escola pode incluir novas práticas, novos letramentos, ou multiletramentos. Assim, incorporam-se novas ferramentas pedagógicas como o celular e o uso da internet em computadores escolares.

Para além da escrita e da leitura grafocêntrica, em ordem sequencial e linear, salientam as autoras que "a leitura no meio digital, por exemplo, realizase alinearmente, não obedecendo a uma sequência e não havendo a ideia de todo previamente existente" (GARCIA; SILVA; FELÍCIO; 2012 p.132).O hipertexto, o jogo, assim como leituras e outros suportes, apresentam diferentes mecanismos de organização e disposição das páginas, como links e variadas "saídas" para continuidades não lineares, incluindo o uso de imagens, gráficos, e outros elementos que requerem inferências e interpretações, o que implica o uso permanente dessas ferramentas pelos sujeitos, considerando a velocidade e diversidade que se movimenta o mundo da Web.

Para essas autoras, faz-se necessário ao trabalhar com o letramento multimidiático, que sejamos éticos, democráticos e críticos. Assim, é importante identificar o que agrega e, refletir sobre ganhos e perdas, "entendendo criticamente como se dá a construção de sentidos" e ainda relacionar os conteúdos com os aspectos contextuais do estudante. Nesse sentido, Lima Santos (2018, p. 24) observa que:

As tecnologias de meio digital trouxeram novas interfaces para as ações de ler e de escrever: teclado e monitor (em vez de caneta e papel), impressora, softwares de edição de texto, navegadores para leitura na internet, ou seja, são tecnologias que se somam às possibilidades já existentes e, portanto, já são familiares ao usuário. 
Acerca do acesso das escolas do campo às tecnologias digitais, Pereira e Lovo (2019), afirmam que entre o ano 2000 e ano 2010 no Brasil foram adotadas diversas políticas e iniciativas de inclusão digital em diversos âmbitos, inclusive escolas do campo receberam equipamentos para terem acesso às tecnologias digitais, como forma de superar o que as autoras denominam de "brecha digital".

O papel da escola mudou significativamente com o surgimento da era tecnológica digital, que trouxe inúmeras alterações no campo político, social e econômico. Sabe-se que as alterações do sistema educacional tradicional ocorrem deforma vagarosa. Porém, diante desse cenário tecnológico, é de suma necessidade uma proposta de inclusão digital (PEREIRA; LOVO 2019; p. 166).

É necessário, portanto, que as novas tecnologias, primeiramente cheguem a todas as escolas, inclusive as do campo, para que assim possam estar integradas às práticas pedagógicas, de forma a fortalecer as aprendizagens, tornando a escola um lugar mais atraente para as crianças e jovens. Conforme afirmam as autoras acima, as escolas devem inserir as tecnologias no sentido de formar cidadãos críticos, responsáveis e conscientes, "deliberando e estabelecendo atividades necessárias ao processo de ensinoaprendizado [...] assumindo posições que favoreçam a todos em sua volta" ( $p$. 167). Entretanto, o panorama de acesso á computadores e a internet nas escolas do campo e da cidade ainda é um longo caminho a ser percorrido pelas políticas públicas para que isso se torne realidade. Conforme nos informa llhéu (2019, p. 1):

[...] a pesquisa TIC Educação 2018 revelou que apenas $34 \%$ das escolas públicas rurais brasileiras possuem computadores com acesso à internet $-46 \%$ sequer têm computadores. A principal razão pela falta de acesso é a pouca infraestrutura da região, seguida do alto custo de conectividade. Já na área urbana, o cenário é mais positivo: $98 \%$ das escolas públicas, municipais ou estaduais, possuem acesso à internet. Ainda assim, o número de computadores em funcionamento não é muito promissor: a maior parte possui menos de 15 computadores com conexão.

A utilização das tecnologias midiáticas adequa-se perfeitamente à proposta dos multiletramentos através de elementos que favoreçam a interação 
linguística com variados gêneros, proporcionando aos educandos vivências e experiências semióticas que somente essas tecnologias podem oferecer, mas antes disso, elas precisam chegar às escolas, com a devida qualidade de acesso e de navegação.

Como observa Lima Santos (2018, p. 24).

O aparecimento dos textos multissemióticos e multimodais encontrados nos meios digitais também acarretou o aparecimento de novas situações de produção de leitura e de autoria... o meio digital permite que o leitor interaja, reproduza, reconstrua o texto e realize intervenções sobre ele das mais diversas naturezas, o conceito de autor e a autoridade que ele evocava, como senhor do conteúdo ali produzido parece estar mais diluído.

A autora salienta ainda que a criação de novas ferramentas e tecnologias de comunicação tem possibilitado a criação de novas possibilidades escritas, que, originam novos gêneros discursivos, entre os quais, o blog, os epulbs, fanclips, entre tantos outros que estão emergindo na atualidade. A "leitura desses novos gêneros não se limita ao verbal escrito, expande-se a signos de outras modalidades de linguagem" (LIMA SANTOS 2018, p.25). Esses novos gêneros discursivos mesclam imagem estática, imagem em movimento, som e vídeo, sendo que, segundo a pesquisadora "já extrapolaram os ambientes digitais, não sendo difícil encontrá-los nos impressos" (LIMA SANTOS 2018, p.25). É comum encontrar em livros didáticos uma diagramação que remete às páginas de sites, simulando hiperlinks e etc..

Dias (2012, p.103) considera que "os professores devem partir dos letramentos que os leitores já possuem, sem menosprezá-los ou criticá-los”. Diz ainda que tais conhecimentos prévios devem ser ampliados "à medida que os alunos interagem com as obras disponibilizadas em ambiente virtual". (DIAS, 2012, p.103). Isso reforça ainda o que entendemos como contextualização das aprendizagens.

Rojo (2012, p. 13) acredita também que o multiletramento apresenta-se como uma característica da atual sociedade multicultural. "[...] o que vemos a nossa volta são produções culturais letradas em efetiva circulação social, como um conjunto de textos híbridos de diferentes letramentos." É nessa perspectiva 
que se evidencia a importância de um trabalho pedagógico empenhado em acolher e dar visibilidade aos múltiplos processos de "letrar-se".

Corroborando o que preconiza Freire (2005), compreendemos que a educação precisa acontecer em sintonia com a realidade do educando. Ao afirmar a necessária coragem do educador, Freire também orienta sobre a responsabilidade e o compromisso que deve emanar das políticas públicas em consonância com os interesses das populações. Assim, afirma: "A educação é um ato de amor, por isso, um ato de coragem. Não pode temer o debate. A análise da realidade. Não pode fugir à discussão criadora, sobre pena de ser uma farsa". (FREIRE 2005, p. 34). E para que as escolas do campo sejam, efetivamente, espaços de educação pautada na realidade dos educandos, é necessário que a aprendizagem da leitura e da escrita resulte na emancipação dos educandos. Em sua obra "A Importância do Ato de Ler" (FREIRE, 1989), também salienta acerca dos processos que hoje chamamos de "letramento":

\begin{abstract}
A leitura do mundo precede sempre a leitura da palavra e a leitura desta implica a continuidade da leitura daquele. $\mathrm{Na}$ proposta a que me referi acima, este movimento do mundo à palavra e da palavra ao mundo está sempre presente. Movimento em que a palavra dita flui do mundo mesmo através da leitura que dele fazemos. De alguma maneira, porém, podemos ir mais longe e dizer que a leitura da palavra não é apenas precedida pela leitura do mundo, mas por certa forma de "escrevê-lo" ou de "reescrevê-lo", quer dizer, de transformá-lo através de nossa prática consciente (FREIRE, 1989, p.13).
\end{abstract}

No âmbito do aprendizado da escrita e da leitura, a educação pode abrirse para um grande leque de possibilidades, aproveitando as ricas experiências contextuais, notadamente no campo, onde as crianças vivem realidades onde são mesclados saberes diversificados, tanto relacionados à dinâmica própria da natureza (ciclos climáticos, plantações etc., quanto a utilização de ferramentas tecnológicas de comunicação (através de aplicativos de redes sociais para interação com pessoas à distância, jogos, produção de vídeos, e entretenimentos diversos).

O exercício da leitura, e, por sua vez, a interação com mecanismos diversos de intervenção social proporcionam aos indivíduos e grupos a participação em eventos e situações em que podem, inclusive, exercer seus 
direitos de cidadania, tais como ações que promovam benefícios para suas comunidades, veiculadas através de redes sociais e outros mecanismos midiáticos.

Entendemos que, uma educação pautada na autonomia proporciona letramentos múltiplos, capacitando os educandos para atuarem de forma efetiva e com qualidade em interações sociais as mais variadas. Nessa linha de compreensão, Souza; Colares; Costa (2018) consideram que através da Educação do Campo muitas experiências são bem vindas à área da leitura e escrita:

Com a Educação do campo, possibilitamos, enquanto escola, múltiplos olhares e ações para o desenvolvimento dos sujeitos que estão inseridos no processo de ensino e aprendizagem, pois suas narrativas, relatos e afazeres diários são enaltecidos durante as práticas escolares [...] como, por exemplo, usar celulares para registrarem seus momentos em Tempo Comunidade e criar um vídeo para ser apresentado em sala; gravar entrevista em vídeo ou áudio com moradores da comunidade para resgatar histórias de tradição oral; acessar Internet para pesquisa de alguns temas da aula; baixar jogos que possam fortalecer as práticas sociais dos alunos ou ainda ajudálos a ler e escrever melhor a partir da aprendizagem em rede (SOUZA; COLARES; COSTA, 2018; p .9).

Essas são atividades simples e que podem ser efetuadas de maneira coletiva e integradas, inclusive proporcionando maior interação entre as pessoas, tendo-se como suporte as ferramentas da tecnologia, utilizadas de acordo com os interesses e o contexto local. Essa proposta leva em consideração a diversidade e a capacidade criativa das comunidades e está em sintonia com a produção do conhecimento através dos multiletramentos, possibilitando inclusive, que guardando a perspectiva ética das autorizações dos textos, sons e imagens, tornar-se um instrumento da promoção da visibilidade de certos grupos sociais, até então opacizados pelo domínio daqueles que detêm os meios de comunicação e que só divulgam aquilo que tende aos seus interesses. 


\section{Escolas do campo, seus contextos e bases legais}

As escolas do campo existem atualmente, a partir de uma concepção de política educacional diferenciada, com uma identidade própria. Podemos afirmar que o marco regulatório da Educação no Campo teve sua formulação a partir do ano de 2002, tendo como base as proposições da nova Lei de Diretrizes e Bases da Educação Nacional (Lei 9394/96).

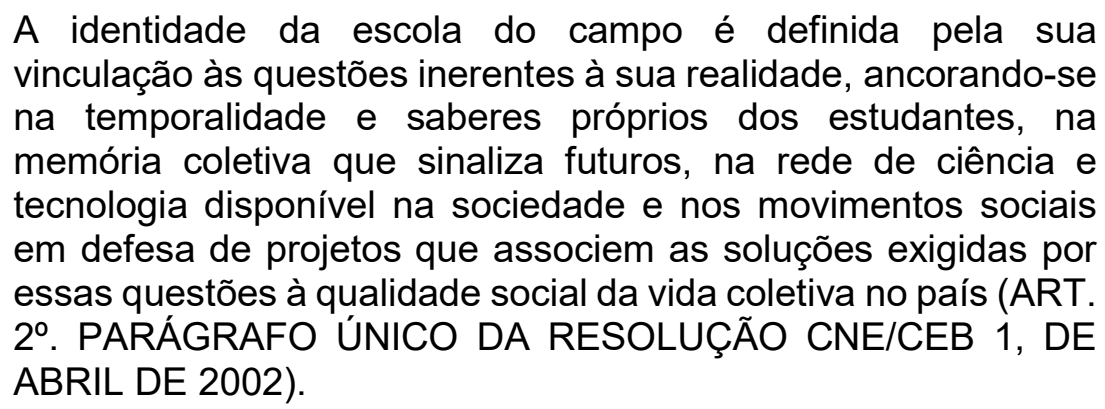

Numa perspectiva mais geral, evidenciamos que a educação tem assumido, no decorrer da história da humanidade, a forma pela qual nos construímos como seres humanos para suprir nossas necessidades. Assim, torna-se imperativo levar em conta a diversidade de povos, de regiões geográficas, novas formas de produção e o avanço acelerado da tecnologia, razões pelas quais a escola deve também desenvolver novas práticas para tornar-se mais próxima e em sintonia com seus educandos e a comunidade onde está inserida.

Assim, superando o modelo de escola que segrega, separa, isola, subordina e aliena, mas outra forma de se fazer escola, capaz de repensar criticamente os modelos educativos homogeneizantes e descontextualizados que não atendem as especificidades e singularidades da população, sejam elas climáticas, culturais ou de outra natureza.

Para Hage (2014), a Educação do Campo por muito tempo careceu assumir um perfil específico, em consonância com os interesses dos povos que o habitam, a exemplo de seringueiros, quilombolas, ribeirinhos, assentados, comunidades tradicionais e outros. Assim, tal diversidade é contemplada através de projetos pedagógicos que representem o perfil dos diversos grupos sociais. As turmas multisseriadas, para esse pesquisador, atendem às necessidades da 
população do campo, constituindo-se um modelo que integra os diversos, possibilitando aprendizagens conjuntas.

Tradicionalmente, como observam Silva e Souza (2014), no Brasil, a educação das classes "subalternas" ficou relegada ao último plano. Registram as autoras que um sistema educacional que contemplasse as pessoas do campo só passou a existir, tardiamente, na década de 1930, quando as oligarquias rurais perdem força a se inicia a industrialização, com o crescimento das populações urbanas. A educação destinada às elites e aquela destinada aos trabalhadores sempre foi amplamente diferente, diferença que é mais acentuada no campo.

Na década de 1940, quando houve a intenção de fixar o homem no campo através do "ruralismo pedagógico", esse tipo de pensamento não serviu para atenuar as verdadeiras condições de abandono em que essa população se encontrava, pois não foi acompanhada de políticas públicas que proporcionassem a melhoria da qualidade de vida dessas comunidades. $\mathrm{Na}$ lei de Diretrizes e Bases da Educação de 1961 fica bem evidente a tentativa de massificação dos estudantes do campo quando a definição de política educacional rural é a extensão do que se propõe para as áreas urbanas (SILVA; SOUZA, 2014).

Distanciada do contexto e das necessidades dos povos do campo, assim como dos seus interesses, a educação do campo continuou excludente. Em 1988, com a atual Constituição brasileira, o acesso a um ensino público e gratuito confirmou-se como direito universal de modo que, conforme explicitam as autoras:

A Constituição, portanto, assegurou o fundamento jurídico constitucional sobre o qual a legislação ordinária regulamentaria e consolidaria a possibilidade do estatuto da educação do campo como constituinte do ordenamento jurídico educacional brasileiro vigente, contemplando a possibilidade do reconhecimento da especificidade da educação do campo (SILVA; SOUZA, 2014, p. 13).

Hage (2014) salienta que desde o final dos anos 1990 as organizações sociais vinculadas aos movimentos que representam as populações do campo 
assumiram uma luta conjunta por uma política educacional que contemplasse suas especificidades. De tal modo,

É interessante destacar quanto à legislação que os movimentos sociais [...] têm conquistado um conjunto importante de instrumentos legais que ampliam a definição de marcos regulatórios de reconhecimento da Educação do Campo enquanto política pública, uma condição necessária para que a universalidade do direito à educação se exerça, respeitando as especificidades dos sujeitos do campo (HAGE, 2014, p.1167).

Dentro desse princípio, a escola do campo, enquanto meio de prover educação pública para essas populações, precisa estabelecer currículos e ações pedagógicas que contemplem a sua realidade social. Nesse sentido, a contextualização exerce papel fundamental, principalmente no aspecto do letramento e produção escrita, como ferramenta de participação social e acesso à cidadania.

\section{A contextualização como prática educativa fundamental à educação do campo}

Uma prática educativa embasada a partir da realidade do educando, representa nas palavras de Reis (2011, p. 71) a criação de "espaços e possibilidades de diálogo permanente entre o conhecimento científico e 0 conhecimento popular, entre o que se aprende na escola e o que se faz como trabalho cotidiano" Para o mesmo autor, o conhecimento científico, dessa maneira, passa a ser, "mediatizado pela realidade, pelas condições concretas de existência das pessoas" (REIS, 2011, p. 71). Esse tipo de conhecimento vinculase, então, à prática cotidiana dos educandos. Isso vale para todos os aspectos, notadamente no que diz respeito à lecto-escrita.

Numa perspectiva que prioriza a educação contextualizada, compete à escola problematizar os saberes locais, para que os educandos, ao compreenderem a realidade, possam dialogar melhor - utilizando o saber científico - com o mundo do qual fazem parte.

Um sujeito enraizado e formado numa concepção de educação contextualizada, que permite o diálogo aprendente entre os diversos conhecimentos, jamais se deixaria enganar por 
processos excludentes e/ou desenraizantes [...] (REIS, 2011, p.103).

Dessa forma, salienta-se a possibilidade de uma educação comprometida com os interesses e o modo de ser e viver dos povos do campo, isso define o que chamamos de contextualização dos estudos e aprendizagens. Observandose o que dizem os documentos e normativas acerca da educação contextualizada, vemos que no atual Plano Nacional de Educação (2014) as metas 7 e 8 que referem-se à Educação do Campo, abrem caminho para que se estabeleça um currículo que atenda a essa população, como explicita a estratégia 7.26:

Consolidar a educação escolar no campo de populações tradicionais, de populações itinerantes e de comunidades indígenas e quilombolas, respeitando a articulação entre os ambientes escolares e comunitários e garantindo: o desenvolvimento sustentável e preservação da identidade cultural; a participação da comunidade na definição do modelo de organização pedagógica e de gestão das instituições, considerada as práticas socioculturais e as formas particulares de organização do tempo; a oferta bilíngue na educação infantil e nos anos iniciais do ensino fundamental, em língua materna das comunidades indígenas e em língua portuguesa; a reestruturação e a aquisição de equipamentos [...] (BRASIL, 2014).

Por sua vez, a estratégia 7.27 trata do currículo das escolas do campo, salientando a proposição de "desenvolver currículos e propostas pedagógicas específicas para educação escolar para as escolas do campo e para as comunidades indígenas e quilombolas, incluindo os conteúdos culturais correspondentes às respectivas comunidades." A Educação do Campo, em especial as escolas multisseriadas, precisam estar incluídas efetivamente não só nas propostas desses documentos, mas em ações concretas de políticas educacionais, por representar uma grande quantidade de estudantes, crianças, adolescentes e jovens (e ainda, adultos).

Sendo relegados ao longo do tempo ao esquecimento e ao descaso por parte dos governantes, as escolas multisseriadas precisam ser objeto de atenção dos poderes públicos, vindo a produzir um ensino que possibilite à sua clientela as condições para se desenvolver e produzir conhecimentos consonantes com os seus modos de existência e sua autonomia. 
No âmbito do município de Juazeiro - BA, o Plano Municipal de Educação (2015) contempla em alguns aspectos, essa proposta de Educação do Campo contextualizada, conforme descrito na estratégia 2.8:

Ampliar tempos e espaços de aprendizagens no campo, considerando os modos de vida das comunidades tradicionais, seu modo de produzir cultural e ambientalmente, através da agroecologia, organização da propriedade, grupos associativistas e cooperativistas, tendo em vista as características locais (PMJ 2015, p. 75).

Dentro dessas perspectivas, entendemos que os modos de vida das populações do campo de forma efetiva, precisam ser pautados no desenvolvimento de ações educativas, em especial por tratar-se da necessidade de um letramento efetivo que possibilite aos indivíduos a interação com os mais diversos instrumentos de participação social.

\section{Classes multisseriadas, heterogeneidade e letramentos}

Destacamos o espaço da multissérie, marcado pela heterogeneidade, como forma privilegiada de organização onde se constroem diversos saberes. Cardoso e Jacomeli (2010) afirmam que as escolas multisseriadas vêm resistindo e adentram o século XXI, como "outra forma de escolarização", fora dos padrões urbanos da homogeneidade. Estas se organizaram em modelos opostos aos "grupos escolares", agrupamento original do ensino público urbano. "As escolas do campo tendem a se efetivarem conforme os padrões urbanos, uma vez que a sociedade capitalista se organiza conforme os padrões urbanoindustriais" (CARDOSO; JACOMELI, 2010, P. 4).

Entretanto, é nesse aspecto que encontramos nas multisséries seu potencial como estratégia de aprendizagem integrada para os sujeitos do campo, valorizando as múltiplas formas de convivência comunitárias, assim como as variadas possibilidades de aprendizagens decorrentes da sua organização específica.

Nesse tipo de organização do espaço escolar, as aprendizagens são compartilhadas e, pelo seu formato interativo, um único professor aprende a lidar com as especificidades do conjunto e as individuais. $O$ trabalho pedagógico em 
classes multisseriadas tem se mostrado essencialmente participativo, num ambiente em que os saberes não são "compartimentados", mas sim, educandos de diferentes níveis de maturidade e aprendizagem convivem e interagem durante todo o período em que estão na escola. Destaque-se também a familiaridade que se presencia nesses ambientes, em que irmãos permanecem juntos na mesma sala, evitando o distanciamento, e assim trazendo maior segurança emocional às crianças. Além disso, a interação entre os educandos se dá de forma contextualizada, tendo o ambiente e a comunidade como parceiros.

Essa foi à tônica do trabalho desenvolvido pelo professor da sala multisseriada objeto de nossa pesquisa para a dissertação de Mestrado. Relato a seguir um momento de observação de aula:

Percebeu-se nitidamente no encaminhamento da atividade e organização dos alunos uma preocupação do professor com quem não sabia escrever convencionalmente. Nesse sentido, formaram-se duplas para realização da atividade sobre o semiárido. Essas crianças saiam pelos arredores da escola observavam, desenhavam e pintavam uma árvore, sempre contando com a ajuda do professor e do seu para tentar ainda escrever o nome da planta, para que serviam.

Os que sabiam ler e escrever, mesmo com algumas lacunas além de fazerem o desenho da planta recebiam estímulos do docente a produzirem um texto escrito maior com início, meio e fim. Por sua vez os pais também contribuíram na realização dessa tarefa, por conhecerem as plantas da região e saberem as suas utilidades, estando aptos a ajudar os filhos nessa empreitada escolar, pois o professor pedia para os alunos procurarem aos pais que plantas da região eles conheciam e tinham no entorno de Maniçoba.

O trabalho culminou com a montagem de um painel montado em uma folha de papel madeira afixado na parede da sala de aula, onde os alunos pregavam com fita adesiva os seus textos em forma de desenhos e produção escrita diversificada e em seguida os apresentava (MARTINS, 2017, p. 137).

Observamos que as crianças que já tinham domínio da escrita eram solidárias nas atividades dos demais, dentro de suas possibilidades, de forma espontânea. Em outro momento, observamos que uma criança chamou à atenção de outra em relação à pronúncia e escrita de uma palavra. O que foi em seguida reforçado pelo professor, confirmando a correção, porém, sem que 
nenhuma das crianças se sentisse constrangida, por ser essa uma prática constante entre professores e alunos, que sempre repetiam a frase a seguir, quando situações apontadas surgiam: "Ninguém sabe tudo, e tudo se aprende". Esses são elementos que destacam a multissérie enquanto espaço interativo ${ }^{2}$, lugar de construção de significados e aprendizagens múltiplas, em que a leitura e a escrita sejam acessíveis para a emancipação e autonomia dos sujeitos.

\section{Palavras conclusivas}

A intenção deste artigo foi apresentar a viabilidade dos multiletramentos em escolas do campo multisseriadas, relacionando-se os aspectos diferenciais dessa modalidade de ensino às maiores possibilidades de exercer uma educação contextualizada, embasada em aspectos da realidade dos educandos.

Pela bibliografia consultada, assim como a partir da pesquisa de campo na escola escolhida, evidenciou-se que os multiletramentos são possíveis na estrutura dessas escolas com perfis tão específicos, uma vez que possibilitam um amplo leque de fazeres pedagógicos, os quais devem estar em sintonia com necessidades e interesses dos educandos do campo.

Assim, a utilização de ferramentas tecnológicas para praticar diversos tipos de interações sociocomunicativas como descritos acima, devem se tornar comum nos espaços multissérie, de forma que os eventos de leitura proporcione acesso a mecanismos e gêneros vaiados. Entendemos que, dessa forma, os educandos do campo podem experimentar maneiras de intervir socialmente na sua realidade mediatizados pelo conhecimento e pelas ferramentas tecnológicas diversas.

A realidade encontrada na escola multisseriada do campo, a partir do olhar específico para a unidade escolar pesquisada, mostra-nos estudantes que interagem com seus pares e constroem conhecimentos de forma conjunta, apoiados por um professor que media aprendizagens diferentes em um ambiente de participação coletiva. No caso específico da escola pesquisada, o suporte

\footnotetext{
${ }^{2}$ À época da pesquisa (2017), registramos que havia cinco computadores com mesas e cadeiras disponíveis em uma sala, os quais eram utilizados pelos educandos para atividades diversas, porém ainda não havia rede de internet disponível no prédio escolar.
} 
tecnológico ainda não está totalmente disponível, podendo ser futuramente explorado em vista de aprendizagens variadas e contextualizadas.

Acreditamos, por fim, que a escola multisseriada do campo é fértil para aprendizagens interativas, participativas e mobilizadoras de multiletramentos em todos os aspectos, e, principalmente no que diz respeito à aprendizagem da lecto-escrita, privilegiando a diversidade e a heterogeneidade, tanto dos educandos, quanto de meios e ferramentas para exercê-las.

\section{Referências}

BRASIL, República Federativa. Câmara dos Deputados. Lein¹3. 005 de 25 de junho de 2014. Aprova o Plano Nacional de Educação e dá outras providências.

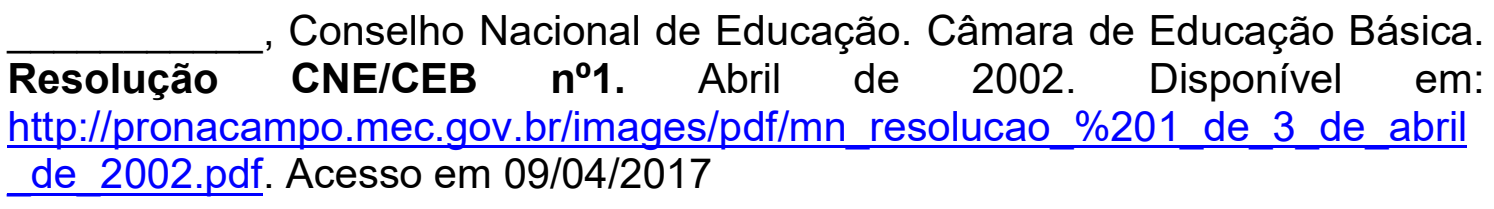

CARDOSO, Maria A.; JACOMELI, Mara R. M. Considerações sobre as Escolas Multisseriadas: Estado da Arte. Revista Educere. Vol. 5 nº 9 jan/jun 2010.

CARVALHO, Luzineide Dourado. Natureza, território e convivência: novas territorialidades no semiárido brasileiro, Jundiaí: Paco Editorial: 2012.

DIAS, Anair V. M. Pedagogia dos Multiletramentos. Diversidade cultural e de linguagens na escola. In: ROJO, Roxane; MOURA, Eduardo (orgs.). Multiletramentos na Escola. São Paulo: Parábola; 2012.

D'AGOSTINI, Adriana. A Educação do Campo e as escolas multisseriadas frente à realidade educacional brasileira. In: D'AGOSTINI, Adriana (org.) Experiências e Reflexões sobre escolas/classes multisseriadas. Florianópolis, Ed. Insular: 2015.

FREIRE, Paulo. Pedagogia da autonomia: saberes necessários à prática educativa. São Paulo: Paz e Terra; 2005.

FREIRE, Paulo. A Importância do ato de Ler em três artigos que se completam. $23^{\text {a }}$ Ed. São Paulo: Cortez; 1989.

GARCIA, C. B.; SILVA, F. D. S.; FELÍCIO, R. P. Projet(o)arte, uma proposta didática. In: ROJO, Roxane; MOURA, Eduardo (orgs.) Multiletramentos na Escola. São Paulo: Parábola, 2012.

HAGE, S.M. Transgressão do Paradigma da (multi) seriação como referência para a construção da escola pública do campo. Educ. Soc., Campinas, v. $35, n^{\circ}$. $129, \quad$ p. 1165-182, out-dez., $2014 . \quad$ Disponível 
em:http://29reuniao.anped.org.br/trabalhos/posteres/GT13-2031--Int.pdf.

Acesso em: 18/03/2020.

ILHÉU, Taís. Pesquisa aponta que a maioria das escolas rurais não tem acesso à internet. In: Guia do Estudante: Atualidades. São Paulo: Editora Abril, 2019. Disponível em: Acessado em 13 de maio de 2020. Disponível em: https://guiadoestudante.abril.com.br/atualidades/pesquisa-aponta-que-amaioria-das-escolas-rurais-nao-tem-acesso-a-internet/

JUAZEIRO, Prefeitura Municipal de. Lei Municipal n. 2.541 de 11 de junho de 2015. Aprova o Plano Municipal de Educação- PME de Juazeiro em consonância com a Lei Federal 12.005 de 25 de junho de 2014, que trata do plano Nacional de Educação PNE - e dá outras providências. Juazeiro: BA: PMJ, 2015.

LIMA, Laurina T. F.; LIMA, E. J. Prática Pedagógica e Multiletramentos em uma Escola Pública de MT (PVA) no PROEMI. In:Revista Áreas Abertas. Disponível em: $\quad$ http://medius.pdl.ifmt.edu.br/media/filer public/f0/9f/f09ff6a6-4653-4825a2bb-

62cfde922291/pratica pedagogica e multiletramentos em uma escola public a de mt pva no proemi.pdf Acesso em: 16/10/2019

LIMA SANTOS, Érica E. Os multiletramentos no chão da Escola: desafiando realidades. Dissertação de Mestrado (2018). Belém: PA: PROFLETRAS. Universidade Federal do Pará, 2018.

MARTINS, Adeilda Ana da Silva. O diálogo entre a educação contextualizada e a aprendizagem nas práticas pedagógicas desenvolvidas em turmas multisseriadas. Dissertação (Mestrado). Juazeiro - BA. Universidade do Estado da Bahia. Departamento de Ciências Humanas. PPGESA. Campus III, 2017.

PEREIRA, T. L.; LOVO, I. C. Um breve panorama da utilização das TDICs pelas escolas rurais. Revista Educação em Debate. Fortaleza, ano $41 ; n^{0} 78$ jan./abr. 2019

REIS, Edmerson dos Santos. Educação do campo: Escola currículo e contexto. Juazeiro - BA. ADAC, 2011.

ROJO, R. Protótipos Didáticos para os multiletramentos. In: ROJO, Roxane; MOURA, Eduardo (orgs.). Multiletramentos na Escola. São Paulo: Parábola; 2012.

SOARES, Magda B. Letramento e Alfabetização: as muitas facetas. Universidade Federal de Minas Gerais. Centro de Alfabetização, Leitura e Escrita. Revista Brasileira de Educação. Jan. labr. 2004. Disponível em: https://www.scielo.br/pdf/rbedu/n25/n25a01.pdf. Acesso em: 12/jan./2020

STREET, Brian V. Letramentos sociais: abordagens críticas do letramento no desenvolvimento, na etnografia e na educação. Trad. Marcos Bagno. São Paulo: Parábola, 2014. 
SILVA, Cacilda G. da; SOUZA, Marta S. L. Salas Multisseriadas: um olhar sobre as práticas educativas construídas na Escola Municipal de Ensino Infantil e Fundamental. Ovídio Tavares de Moraes. Monografia (2014) Universidade Federal da Paraíba. João Pessoa: UFPB, 2014.

SOUZA, E. D; COLARES, G.S.; COSTA, M. R. Multiletramentos na Educação do Campo. In: Revista Projeção e Docência, v9, n², ano 2018, p. 119. Disponível em:

http://revista.faculdadeprojecao.edu.br/index.php/Projecao3/article/view/1125.

Acesso em: 21/01/2020.

\section{Sobre os autores}

\section{Adeilda Ana Silva Martins}

adeildamartins@hotmail.com

UNEB (Universidade do Estado da Bahia - Departamento de Ciências Humanas - Juazeiro - BA.

\section{Edmerson Dos Santos Reis}

edmerson.uneb@gmail.com

Possui graduação em Pedagogia Habilitação Em Educação de Adultos pela Faculdade de Filosofia Ciências e Letras de Juazeiro (1995), Mestrado em Educação - Université du Quebéc a Chicoutimi (2003) e Doutorado em Educação pela Universidade Federal da Bahia (2009). Atualmente é Professor Titular do Departamento de Ciências Humanas - DCH-III/Universidade do Estado da Bahia, Membro do Fórum Nacional de Educação - FONEC, Membro da Secretaria Executiva da Rede de Educação da Semiárido Brasileiro - RESAB; Professor Permanente do Programa de Pós-graduação - Mestrado em Educação, Cultura e Territórios Semiárido da Universidade do Estado da Bahia - UNEB/DCH-III, em Juazeiro - BA. 